\title{
Ultrastructural study of morphological changes in Schistosoma mansoni after in vitro exposure to the monoterpene rotundifolone
}

\author{
Thiago José Matos-Rocha ${ }^{[1],[2], ~ M a r i ́ l i a ~ G a b r i e l a ~ d o s ~ S a n t o s ~ C a v a l c a n t i[~}{ }^{[1],[2],}$ \\ José Maria Barbosa-Filho ${ }^{[3]}$, Ana Silvia Suassuna Carneiro Lúcio ${ }^{[3]}$, Dyana Leal Veras ${ }^{[1],[2],}$ \\ Márcia Ortiz Mayo Marques ${ }^{[4]}$, Luiz Carlos Alves ${ }^{[1],[2]}$ and Fábio André Brayner ${ }^{[1],[2]}$
}

\begin{abstract}
[1]. Centro de Pesquisas Aggeu Magalhães, Departamento de Parasitologia, Laboratório de Biologia Celular e Molecular, Recife, PE, Brasil.
[2]. Universidade Federal de Pernambuco, Laboratório de Imunopatologia Keizo Asami, Recife, PE, Brasil. [3]. Universidade Federal da Paraíba, João Pessoa, PB, Brasil. [4]. Centro de Pesquisa e Desenvolvimento de Recursos Genéticos Vegetais, Instituto Agronômico de Campinas, Campinas, São Paulo, Brasil.
\end{abstract}

\begin{abstract}
Introduction: Schistosomiasis, a parasitic disease caused by trematode flatworms of the genus Schistosoma, affects more than 200 million people worldwide, and its control is dependent on a single drug, praziquantel. Here, we report the in vitro effect of rotundifolone, a monoterpene isolated from Mentha x villosa (Lamiaceae), on Schistosoma mansoni adult worms. Methods: The in vitro effect of rotundifolone on adult Schistosoma mansoni was evaluated by analysis of behavior and mortality and through a scanning electron microscopic analysis of ultrastructural changes in the tegument of the worms. Results: At concentrations of 3.54 and $7.09 \mu \mathrm{g} / \mathrm{mL}^{-1}$ rotundifolone, no worm mortality was observed at any of the sampling intervals. A minor reduction in movement of the tail, suckers, and gynecophoral canal membrane was observed after $96 \mathrm{~h}$ of exposure to $7.09 \mu \mathrm{g} / \mathrm{mL}^{-1}$ rotundifolone. At $70.96 \mu \mathrm{g} / \mathrm{mL}^{-1}$, a lack of movement was observed from $72 \mathrm{~h}$ onwards and all worms were deemed dead; similar effects were observed at $48 \mathrm{~h}$ with $177.4 \mu \mathrm{g} / \mathrm{mL}^{-1}$, and at $24 \mathrm{~h}$ with $354.8 \mu \mathrm{g} / \mathrm{mL}^{-1}$ and $700.96 \mu \mathrm{g} / \mathrm{mL}^{-1}$. Rotundifolone also caused death of all parasites and separation of coupled pairs into individual males and females after $24 \mathrm{~h}$ at $354.8 \mu \mathrm{g} / \mathrm{mL}^{-1}$. Conclusions: The main changes in the tegument induced by the different ROT treatments were: after 24h incubation, bubble lesions spread over the entire body and loss of tubercles occurred in some regions of the ventral region.
\end{abstract}

Keywords: Schistosomicidal activity. Schistosoma mansoni. Mentha x villosa. Rotundifolone.

\section{INTRODUCTION}

Schistosomiasis is a parasitic disease caused by trematode flatworms of the genus Schistosoma that is common in many tropical countries and affects more than 207 million people living in conditions of poor sanitation and/or with less developed social infrastructure ${ }^{1}$. Chemotherapy is the only immediate recourse to minimize the prevalence and incidence of this disease worldwide ${ }^{2}$. At present, praziquantel (PZQ) is the drug of choice for the treatment of all forms of schistosomiasis ${ }^{3}$. However, dependence on a single drug is a concern because of the possible development of resistance in some strains $\mathrm{s}^{4,5}$. A second drug, oxamniquine (OXA), acts against Schistosoma mansoni, which is found in Africa, and against Schistosoma haematobium in South America, where it is the only species

Corresponding author: Dr. Thiago José Matos Rocha.

e-mail: thy_rocha@hotmail.com

Received 16 September 2016

Accepted 17 January 2017 of this genus present. OXA is manufactured in Brazil by Pfizer ${ }^{6}$. OXA has a complicated manufacturing process, with large fermentation tanks required for its biological synthesis, resulting in a higher cost than that required for PZQ synthesis. Due to this difficulty, PZQ is generally the only drug utilized at the moment ${ }^{7}$.

Praziquantel is a pirazyl isoquinoline and is effective against all Schistosoma species infecting humans; ; it has been successfully used over the last 20 years as the drug of choice in most areas where the disease is endemic ${ }^{9-11}$. Although PZQ has several advantages, including tolerability, safety, efficacy, and low cost, it does not protect individuals from reinfection and is not active against the immature stages of the worm, such as the schistosomula, pre-adult and juvenile adult stages ${ }^{12}$. Therefore, there is an urgent need to identify new drugs that can combat S. mansoni.

Investigative methods such as scanning electron microscopy (SEM) have been employed to study the effects of compounds on the tegument of many helminthes ${ }^{13}$, especially S. mansoni ${ }^{14}$. In this context, the search for natural bioactive compounds against 
S. mansoni offers a potentially valuable approach ${ }^{15,16}$. Members of the plant family Lamiaceae have been widely studied as a source of secondary metabolites with biological activity ${ }^{17,18}$. Among the species of this family, Mentha $x$ villosa Hudson has been used in traditional medicine owing to its antiparasitic properties. It is known popularly as hortelã-rasteira, hortelã comum, or hortelã-da-folha-miúda ${ }^{19}$. A commercial formulation named Giamebil@, which has as its active compound the dry extract from the leaves and stem of M. $x$ villosa, has been shown to have amebicidal (Entamoeba histolytica) and giardicidal (Giardia lamblia) activities ${ }^{20}$. Recent studies have also demonstrated the efficacy of extract from $M . x$ villosa against Trichomonas vaginalis infection ${ }^{21}$.

Rotundifolone (ROT) is a monoterpene that is present in large amounts in the leaves of M. $x$ villosa. This study had greater impact to ROT, because it represents more than $50 \%$ (can reach 70\%) of the total essential oil from Mentha x villosa (MVEO) reported previously ${ }^{17}$. It has the chemical formula $\mathrm{C}_{10} \mathrm{H}_{14} \mathrm{O}_{2}$ (Figure 1) and a molecular weight of 166. ROT is an important chemical constituent of the essential oil of many Mentha species (M. rotundifolia, M. suaveolens, M. spicata, M. longifolia, and M. $x$ villosa $)^{21}$. It has been reported to have hypotensive and bradycardic ${ }^{22}$, antimicrobial ${ }^{23}$, spasmolytic ${ }^{24}$, larvicidal ${ }^{25}$, antitumour effects ${ }^{26}$ and schistosomicidal activity on adult $S$. mansoni ${ }^{27}$.

Considerable efforts are underway to develop novel drugs for prevention and cure of schistosomiasis. Recent studies by our research group have demonstrated that ROT has in vitro schistosomicidal activity ${ }^{17}$. However, there are no studies on the possible ultrastructural changes in adult $S$. mansoni that are induced by treatment with ROT.

\section{METHODS}

\section{Ethical considerations}

All experiments involving the use of experimental animals were performed in accordance with the ethical standards of the Foundation Oswaldo Cruz and were approved by the Animal Experimentation Ethics Committee (No. 06/2010).

\section{Botanical material}

Fresh leaves of M. $x$ villosa were collected from the Medicinal Plants Garden of the Pharmaceutical Technology Laboratory, Federal University of Paraiba (LTF/UFPB) between April and June 2011. The plants were identified and authenticated by Dr. F. J. Abreu Matos (Laboratory of Natural Products, Federal University of Ceará) and by Dr. Raymond Harley of the Royal Botanic Gardens, Kew, England. A voucher specimen was deposited in the Prisco Bezerra Herbarium of the Federal University of Ceará (N. 14996).

\section{Isolation and identification of rotundifolone}

To extract MVEO, $10 \mathrm{~kg}$ of leaves were steam-distilled for $8 \mathrm{~h}$. The oil obtained $(0.1 \%)$ was dried over anhydrous sodium sulfate in the usual manner and stored at $4{ }^{\circ} \mathrm{C}^{13}$. We used a gas chromatograph coupled to a mass spectrometer (Shimadzu QP-5000) under the following analytical conditions: capillary

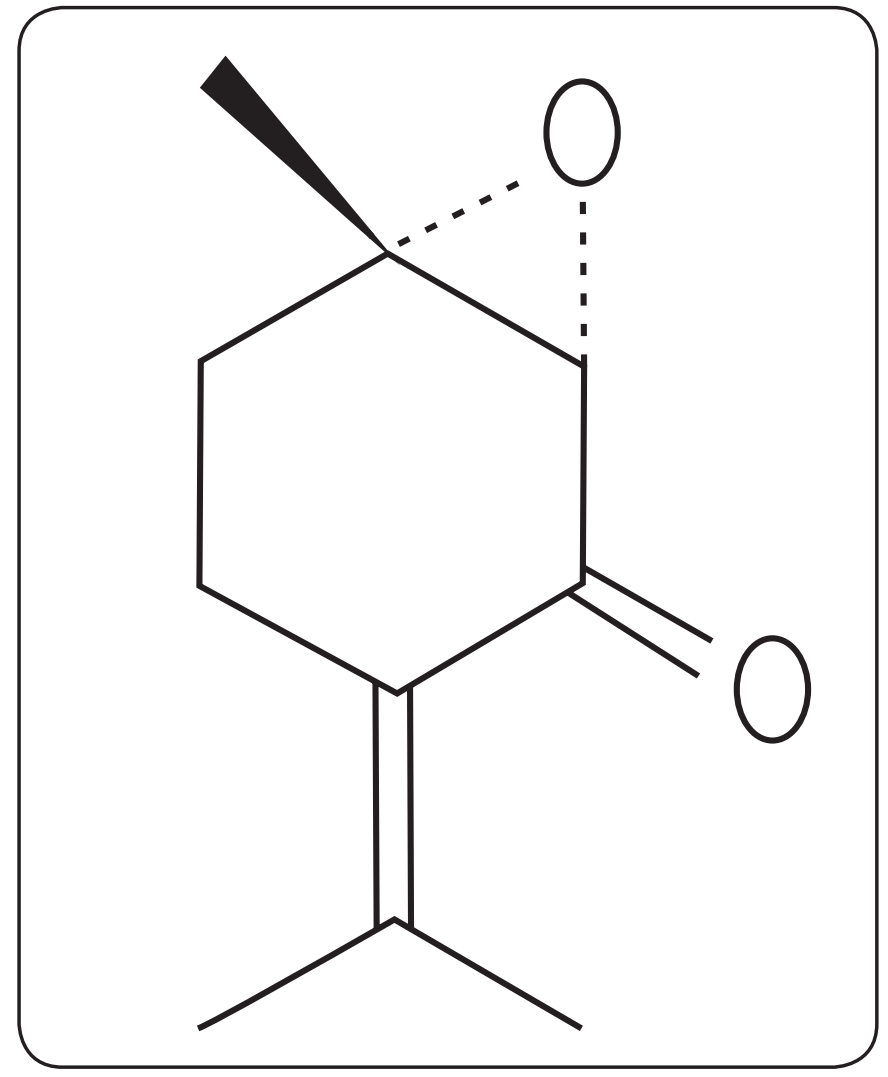

FIGURE 1 - Chemical structure of rotundifolone.

column, OV-5 $(30 \mathrm{~m} \times 0.25 \mathrm{~mm} \times 0.25 \mu \mathrm{m})$; injector (Ohio Valley Specialty Chemical, Inc.), $240^{\circ} \mathrm{C}$; detector, $230^{\circ} \mathrm{C}$; electron impact, $70 \mathrm{eV}$; gasdrag, $\mathrm{He}$; flow, $1.0 \mathrm{~mL} / \mathrm{min}^{-1}$; split, 1/20; program temperature, $60-240^{\circ} \mathrm{C}$ at $3^{\circ} \mathrm{C} \mathrm{min}^{-1}$; and solution injection volume, $1 \mu \mathrm{L}(1 \mu \mathrm{L}$ of essential oil per $1 \mathrm{~mL}$ of ethyl acetate). The compounds were identified by comparing their mass spectra using the Gas Chromatography Mass Spectrometry (GC-MS) database system (Nist 62 lib.) and the Kovats retention index.

The oil was subjected to preparative layer chromatography (Merck silica gel PF254 plates, $40 \times 20 \mathrm{~cm}$ ). The plates were eluted three times using hexane as the solvent. Pure ROT (Figure 1) was thereby obtained from M. $x$ villosa leaves. The chemical purity of ROT (more than 99.9\%) was determined by high-performance liquid chromatography.

\section{Maintenance and collection of adult Schistosoma mansoni}

Schistosoma. mansoni strain BH (Belo Horizonte, Minas Gerais, Brazil) was used in this study. The parasites were maintained in Biomphalaria glabrata snails and Swiss strain mice in the laboratory at the Aggeu Magalhães Research Center of the Oswaldo Cruz Foundation. Female Swiss mice weighing $20 \pm 5 \mathrm{~g}$ were used as the definitive host and infected transcutaneously with about 120 cercariae (this is the number of cercariae needed to ensure infection of a single mouse) using 
the tail immersion technique. The animals were kept under controlled temperature and light conditions and had ad libitum access to food and water.

At 55 days after infection, adult $S$. mansoni were recovered from the hepatic portal system of infected mice and left for $2 \mathrm{~h}$ to adapt to the culture medium, washed in RPMI 1640 medium buffered with HEPES $(20 \mathrm{mM}), \mathrm{pH} 7.5$, supplemented with penicillin $\left(100 \mathrm{IU} / \mathrm{ml}^{-1}\right)$, streptomycin $\left(100 \mu \mathrm{g} / \mathrm{mL}^{-1}\right)$ and $10 \%$ fetal bovine serum (Gibco), and placed in petri dishes containing $2 \mathrm{~mL}$ of sterile culture medium ${ }^{17}$.

\section{In vitro antischistosomal assay}

The in vitro assays of antischistosomal treatments were carried out using ROT dissolved in $100 \%$ DMSO. Five worms were placed into each well and incubated at $37^{\circ} \mathrm{C}$ in an atmosphere containing $5 \% \mathrm{CO}_{2}$. After $2 \mathrm{~h}$ to adapt to the culture medium, MVEO and ROT (3.5, 7.0, 71, 177.4, and $354.8 \mu \mathrm{g} / \mathrm{mL}^{-1}$ ) were added. As a negative control, adult worms were incubated in RPMI 1640 and RPMI $1640+1.6 \%$ DMSO. As a positive control, worms were incubated in $0.5 \mu \mathrm{g} /$ $\mathrm{mL}^{-1}$ PZQ. The worms were monitored every $24 \mathrm{~h}$ until $120 \mathrm{~h}$ and changes in motor activity were assessed and the mortality rate was determined ${ }^{27}$. The evaluation of the viability of adult worms was based on the standard procedures for screening schistosomicidal compounds established by the World Health Organization (WHO) Special Program for Research and Training in Tropical Diseases. In this evaluation system, $(+++)$ indicates normal activity, $(++)$ slight loss of movement, with active tail, suckers, and gynecophoral canal membrane, $(+)$ indicates movement of tails and suckers alone, and (-) indicates no movement. The worms were considered to be dead when no movement was identified after 3 min of observation using an inverted microscope ${ }^{27}$.

\section{Scanning electron microscopy}

Scanning electron microscopy was used to evaluate morphological changes in S. mansoni worms after the in vitro treatments. Worms were incubated for $24 \mathrm{~h}$ and after their death naturally they were washed in sodium cacodylate buffer $(\mathrm{pH}$ $=7.2)$, fixed in $2.5 \%$ glutaraldehyde $(\mathrm{pH}=7.4)$ for $24 \mathrm{~h}$, and then fixed in $1 \%$ osmium tetroxide for $1 \mathrm{~h}$. The samples were dehydrated through an ethanol series, dried in a critical point dryer, and then mounted on stubs and coated with gold using a sputter coater. The specimens were examined using a JEOL$5600 \mathrm{LV}$ microscope ${ }^{27}$.

\section{RESULTS}

\section{In vitro effects of rotundifolone on Schistosoma mansoni adult worms}

At ROT concentrations of 3.5 and $7.0 \mu \mathrm{g} \mathrm{mL}^{-1}$, no worm mortality was observed during the course of the experiment. A minor loss of movement of the tail, suckers, and gynecophoral canal membrane was observed after $96 \mathrm{~h}$ exposure to $7 \mu \mathrm{g} / \mathrm{mL}^{-1}$ ROT. Worms in the negative control groups (RPMI 1640 and RPMI 1640 + DMSO 1.6\%) remained viable throughout the analysis period. In the positive control with PZQ, all parasites died within $24 \mathrm{~h}$. At $71 \mu \mathrm{g} \mathrm{mL}^{-1}$ ROT, mortality and absence of movement were observed from $72 \mathrm{~h}$; similar effects were apparent from $48 \mathrm{~h}$ exposure to $177.4 \mu \mathrm{g} / \mathrm{mL}^{-1} \mathrm{ROT}$, and from $24 \mathrm{~h}$ exposure to $354.8 \mu \mathrm{g} \mathrm{mL}^{-1}$ and $700.96 \mu \mathrm{g} \mathrm{mL}^{-1}$ ROT (Table 1).

\section{Ultrastructural analysis of rotundifolone-induced morphological changes in Schistosoma mansoni}

Adult worms in the control groups showed no changes in behavior up to $120 \mathrm{~h}$ and remained vigorous during this time. Male worms in the control groups had a tegument that was covered with tubercles and tiny projections (spines). The back was long and contained the gynecophoral canal. The area between the oral and ventral suckers did not have any tubercles, spines, or sensory papillae (Figure 2A and Figure 2B). A large number of tubercles with typical spines (Figure 2C) as well as sensory papillae (Figure 2D) was observed.

After treatment with PZQ, all worms were dead by $24 \mathrm{~h}$ of incubation. Under SEM, adult worms treated with $0.5 \mu \mathrm{g} / \mathrm{mL}^{-1}$ PZQ showed a spiral-shaped body (Figure 2E). The tegument
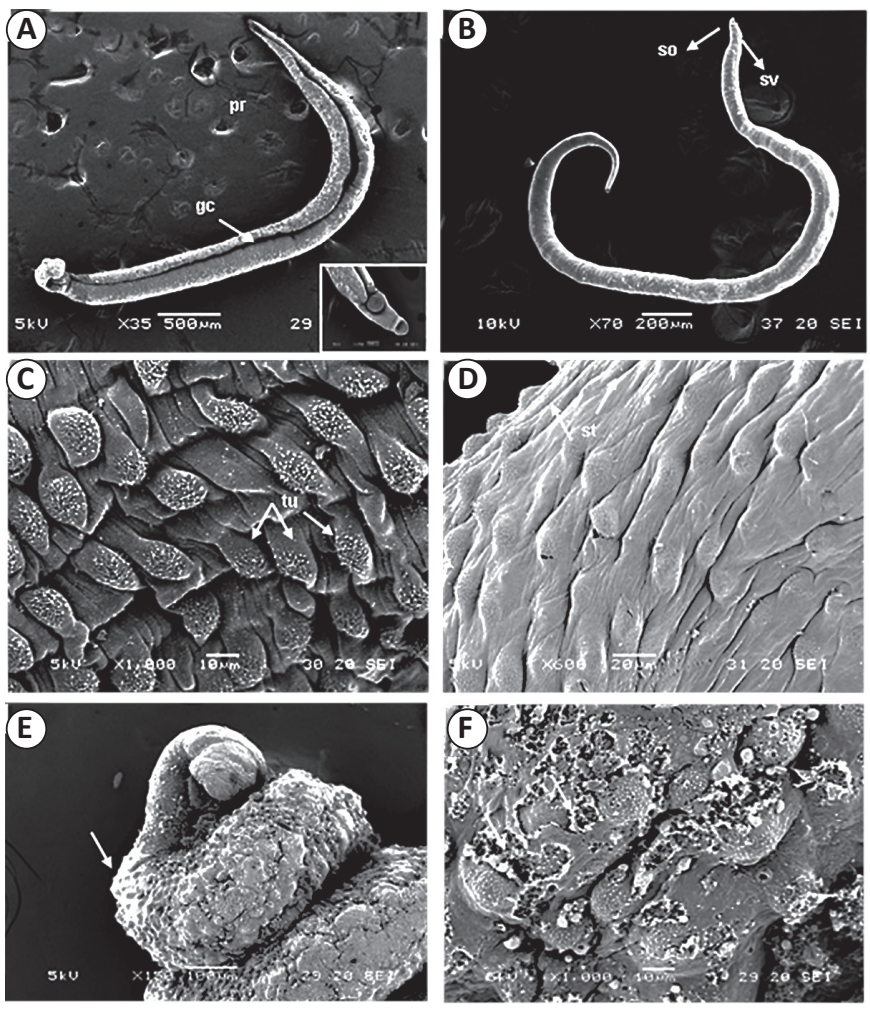

FIGURE 2 - (A-F) Micrographs of adult Schistosoma mansoni worms. (A-B) Micrographs of untreated adult worms. The micrograph of an untreated male shows the gynecophoral canal (gc) and the thinner posterior region (pr). (B) The anterior region of a female Schistosoma mansoni with an oral sucker (os) and ventral sucker (sv). (C) Tubercles (tu) with spines are present on the tegument of a male. (D) Grooves (arrows) are present in the testa (st). (E-F) Micrographs of adult worms treated with PZQ $\left(0.5 \mu \mathrm{g} / \mathrm{mL}^{-1}\right)$ : (E) Worm showing a twisted body shape (arrow) and extensive destruction of the tegument. (F) Worm showing severe damage to the seed coat, with loss of spicules and extensive ulceration of the tegument (arrows). PZQ: praziquantel. 
TABLE 1

In vitro effect of different concentrations of rotundifolone on mortality of adult Schistosoma mansoni.

\begin{tabular}{lccc}
\hline Groups & Incubation period (h) & Number of dead worms (\%) & Changes in motor activity \\
\hline Control & 120 & - & ++ \\
DMSO $1 \%$ & 120 & - & ++ \\
PZQ & 24 & - & ++ \\
$0.7 \mu \mathrm{g} \mathrm{mL}-1$ & 120 & - & + \\
$3.54 \mu \mathrm{g} / \mathrm{mL}^{-1}$ & 120 & - & ++ \\
$7.09 \mu \mathrm{g} / \mathrm{mL}^{-1}$ & 96 & 100.0 & ++ \\
$70.96 \mu \mathrm{g} / \mathrm{mL}^{-1}$ & 72 & 100.0 & - \\
$177.4 \mu \mathrm{g} / \mathrm{mL}^{-1}$ & 48 & 100.0 & - \\
$354.8 \mu \mathrm{g} / \mathrm{mL}^{-1}$ & 24 & 100.0 & - \\
$700.96 \mu \mathrm{g} / \mathrm{mL}^{-1}$ & 24 & - \\
\hline
\end{tabular}

Negative control (RPMI 1640; DMSO + RPMI 1640). Positive control with $0.5 \mu \mathrm{g} / \mathrm{mL}^{-1}$ PZQ. Rotundifolone: +++ normal activity; ++ slight loss of movement, with activity of the tail, suckers, and gynecophoral canal membrane. RPMI 1640: Roswell Park Memorial Institute; DMSO: dimethyl sulfoxide; PZQ: praziquantel.

showed loss of tubercles and spines and many regions were ulcerated (Figure 2F).

The main changes in the tegument induced by the different ROT treatments were: after $24 \mathrm{~h}$ incubation at $354.8 \mu \mathrm{g} / \mathrm{mL}^{-1}$ ROT, bubble lesions spread over the entire body (Figure 3A) and loss of tubercles occurred in some regions of the ventral region (Figure 3B); after $48 \mathrm{~h}$ incubation at $177.4 \mu \mathrm{g} / \mathrm{mL}^{-1} \mathrm{ROT}$, increased rate of death of worms, which showed destruction of the oral sucker and contraction of the ventral sucker (Figure 3C). The severity of the lesion in the tegument lesion increased after $72 \mathrm{~h}$ of ROT treatment $\left(71 \mu \mathrm{g} / \mathrm{mL}^{-1}\right)$ ( Figure 3D). The lowest ROT concentrations $\left(3.54\right.$ and $\left.7.09 \mu \mathrm{g} / \mathrm{mL}^{-1}\right)$ did not cause mortality of adult worms after $120 \mathrm{~h}$ of exposure; however, changes in the tegument of the worms were observed. At $7.09 \mu \mathrm{g} / \mathrm{mL}^{-1}$ ROT, damage to the tegument was seen at higher magnifications (Figure 3E) and in the worms treated with $3.54 \mu \mathrm{g} / \mathrm{mL}^{-1}$ there was destruction of some tubercles (Figure 3F).

\section{DISCUSSION}

The tegument of $S$. mansoni is an important structure that is involved in both absorption of nutrients and secretion of some products; it also has a role in protecting the organism from the immune response of the host. Therefore, the tegument is a critically important target for antischistosomal drugs ${ }^{28}$. Electron microscopic analyses, including TEM, have documented damage to the tegument of $S$. mansoni caused by exposure to synthetic and natural compounds ${ }^{14}$ for various antischistosomal prototype compounds ${ }^{29}$.

Recently, in vitro studies for new active compounds against S. mansoni ${ }^{14-16}$ showed that ROT, a monoterpene found in Mentha species, showed promising antischistosomal properties against adult schistosomes ${ }^{17,27}$.

Matos-Rocha et al. ${ }^{17}$ determined the composition of MVEO and evaluated its in vitro effects on the viability of adult S. mansoni. The main constituents of MVEO were identified as ROT $(70.96 \%)$, limonene $(8.75 \%)$, trans-caryophyllene $(1.46 \%)$, and $\beta$-pinene $(0.81 \%)$. In viability tests, neither trans-
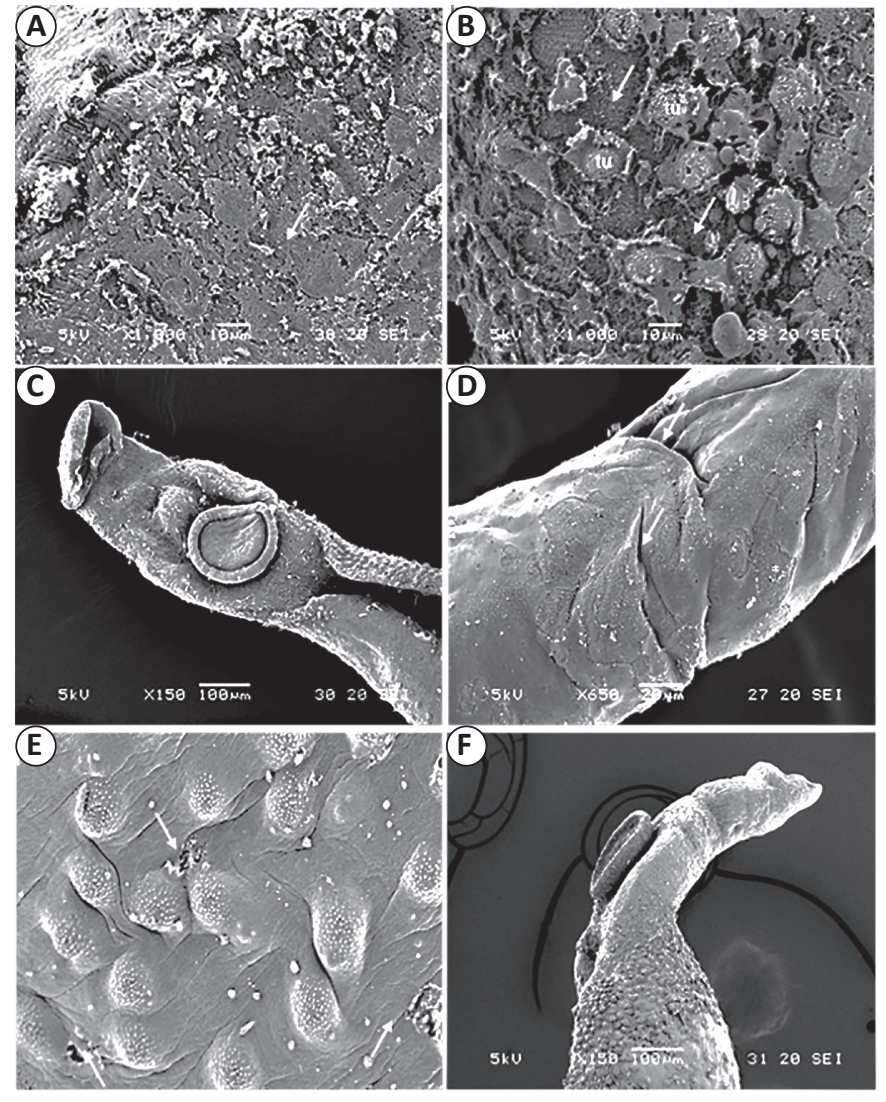

FIGURE 3 - (A-F) Micrographs of adult Schistosoma mansoni treated with different concentrations of ROT. (A) $24 \mathrm{~h}$ incubation with $700.96 \mu \mathrm{g} / \mathrm{mL}^{-1}$, ROT induced disarray in the tegument (arrows); it was not possible to identify tubercles and spikes. (B) Adult Schistosoma mansoni after a 24-h incubation with $354.8 \mu \mathrm{g} / \mathrm{mL}^{-1}$ ROT show minor damage compared to the highest concentration, and it was possible to identify tubercles (tu); between the tubercles, note sloughing of the tegument (arrow). (C) Anterior region of an adult worm after $48 \mathrm{~h}$ incubation with $177.4 \mu \mathrm{g} / \mathrm{mL}^{-1} \mathrm{ROT}$. There is clear damage to the oral sucker oral (so) and ventral sucker (sv). (D) After $72 \mathrm{~h}$ exposure to $71 \mu \mathrm{g} / \mathrm{mL}^{-1} \mathrm{ROT}$, the worm shows a flattened appearance and has a twisted tegument (arrow) and superficial ulceration (asterisk). (E) Adult worms after $96 \mathrm{~h}$ in $7.1 \mu \mathrm{g} / \mathrm{mL}^{-1}$ ROT. Vesicles have formed (arrow). (F) After $120 \mathrm{~h}$ of incubation with $3.5 \mu \mathrm{g} / \mathrm{mL}^{-1}$ ROT, no tubercles can be identified. ROT: rotundifolone. 
caryophyllene or $\beta$-pinene had anti-schistosomicidal activities. Rather, the schistosomicidal activity of MVEO appeared to be due to ROT, its major constituent. When analyzed alone, ROT showed similar activity to MVEO. To date, the possible effects of ROT on the ultrastructure of $S$. mansoni has not been examined.

The results of this study show that all tested concentrations, ROT was able to cause damage to the tegument of $S$. mansoni. These findings corroborate the report of Lima et al. ${ }^{14}$ in which they investigated the characteristics of the tegument of adult worms obtained from mice infected with cercariae of S. mansoni and subjected to treatment with allicin at a concentration of $20 \mathrm{mg} / \mathrm{mL}^{-1}$. Lima et al. ${ }^{14}$ found a variety of structural changes to the tegument of the worms, including destruction of tubercles, and induction of edema and ulcers. In addition, there were changes to the number and volume of thorns and the tubercles showed a modified appearance. In the present study, there was a marked difference in the morphology of worms treated with PZQ compared with ROT. Macroscopic examination of adult S. mansoni exposed to PZQ found that they showed muscle contractions that caused them to stay in a retracted or twisted shape. This behavior was not observed in worms treated with MVEO and its constituents.

Mendonça et al. ${ }^{30}$ compared the in vitro anthelminthic effect of PZQ against recent $S$. mansoni isolates by estimating relative motility, survival indices, and tegumental surface alterations. They found that the damage caused by PZQ on the integument of adult worms was dose-dependent, and increased with increasing PZQ concentrations.

The mechanism by which ROT exerts its in vitro effect on $S$. mansoni is not clear. It has been suggested that, because of the large number of constituents, essential oils may have no specific cellular target ${ }^{31}$. Additionally, as the lipophilic compounds present in essential oils can pass through the cell wall, integument, and cytoplasmic membrane, they may damage the structure of the cellular membranes during their passage, which may cause cellular lysis ${ }^{32,33}$. Regarding their biological properties, some of the activities of essential oils are associated with loss of ions and reduction of membrane potential, as well as collapse of the proton pump and depletion of the ATP pool ${ }^{34,35}$.

Our analyses here demonstrate the effectiveness of ROT as a candidate compound with significant in vitro effects against $S$. mansoni adult worms. This monoterpene was able to cause morphological alterations in the tegument of adult schistosomes. Overall, these results are important as there is an urgent need to develop new agents against schistosomes. Because ROT is generally recognized as safe, this compound may have broad antiparasitic applications. We recommend further analysis to better understand the in vivo efficacy of this new potential treatment for schistosomiasis.

\section{Conflict of interest}

The authors declare that there is no conflict of interest.

\section{Acknowledgments}

To Laboratório de Tecnologia Farmacêutica/Universidade Federal da Paraiba (LTF/UFPB), Laboratório de Imunopatologia Keizo Asami (LIKA/ UFPE) and Núcleo de Plataformas Tecnológicas (NPT) of Aggeu Magalhães
Research Center of the Oswaldo Cruz Foundation for support for the experiments and to CAPES for a scholarship.

\section{REFERENCES}

1. Rollinson D, Knopp S, Levitz S, Stothard JR, Tchuenté LA, Garba A, et al. Time to set the agenda for schistosomiasis elimination. Acta Trop. 2013;128(2):423-40.

2. Hotez PJ, Molyneux DH, Fenwick A, Kumaresan J, Sachs SE, Sachs JD, et al. Control of neglected tropical diseases. N Engl J Med. 2007;357(10):1018-27.

3. Cioli D, Pica-Mattoccia L. Praziquantel. Parasitol Res. 2003;90(Suppl 1):S3-S9.

4. Stelma FF, Talla L, Sow S, Kongs A, Niang M, Polman K, et al. Efficacy and side effects of praziquantel in an epidemic focus of Schistosoma mansoni. Am J Trop Med Hyg. 1995;53(2):167-70.

5. Fallon PG, Sturrock RF, Niang AC, Doenhoff MJ. Short report: diminished susceptibility to praziquantel in a Senegal isolate of Schistosoma mansoni. Am J Trop Med Hyg. 1995;53(1):61-2.

6. Cheetham PSJ, Cabral JMS, Best D, Boross L, Tramper J. Case studies in applied biocatalysis from ideas to products, editors. Applied Biocatalysis, Harwood Academics Publishers GmbH, 1994. p. 47-108.

7. Araujo N, Mattos AC, Coelho PM, Katz N. Association of oxamniquine praziquantel and clonazepam in experimental Schistosomiasis mansoni. Mem Inst Oswaldo Cruz. 2008;103(8):7815 .

8. World Health Organization (WHO). Schistosomiasis: number of people treated worldwide in 2009. Wkly Epidemiol Rec. 2011;86(9):73-80.

9. Ridi RE, Aboueldahab M, Tallima H, Salah M, Mahana Fawzi NS, Mohamed SH, et al. In vitro and in vivo activities of arachidonic acid against Schistosoma mansoni and Schistosoma haematobium. Antimicrob Agents Chemother. 2010;54(8):3383-9.

10. de Moraes J, de Oliveira RN, Costa JP, G Junior AL, de Sousa DP, Freitas RM, et al. Phytol, a diterpene alcohol from chlorophyll, as a drug against neglected tropical disease Schistosomiasis mansoni. PLoS Negl Trop Dis. 2014;8(1):e2617.

11. Bertão HG, da Silva RA, Padilha RJ, de Azevedo Albuquerque MC, Rádis-Baptista G. Ultrastructural analysis of miltefosine-induced surface membrane damage in adult Schistosoma mansoni BH strain worms. Parasitol Res. 2012;110(6):2465-73.

12. Holtfreter MC, Loebermanna M, Klammta S, Sombetzkia M, Bodammera P, Riebolda D, Kinzelbachb R, Reisinger EC. Schistosoma mansoni: schistosomicidal effect of mefloquine and primaquine in vitro. Exp Parasitol. 2011;127(1):270-6.

13. Aires AL, Ximenes EC, Silva RA, Barbosa VX, Góes AJ, Peixoto CA. Ultrastructural analysis of $\beta$-lapachone-induced surface membrane damage in male adult Schistosoma mansoni BH strain worms. Exp Parasitol. 2014;142(1):83-90.

14. Lima CM, Freitas FI, Morais LC, Cavalcanti MG, Silva LF, Padilha RJ. Ultrastructural study on the morphological changes to male worms of Schistosoma mansoni after in vitro exposure to allicin. Rev Soc Bras Med Trop. 2011; 44(3):327-30.

15. Silva AP, Silva MP, Oliveira CG, Monteiro DC, Pinto PL, Mendonça RZ. Garcinielliptone FC: antiparasitic activity without cytotoxicity to mammalian cells. Toxicol In Vitro. 2015;29(4):681-7.

16. Dejani NN, Souza LC, Oliveira SR, Neris DM, Rodolpho JM, Correia RO, et al. Immunological and parasitological parameters in Schistosoma mansoni-infected mice treated with crude extract from 
the leaves of Mentha x piperita L. Immunobiology. 2014;219(8):62732 .

17. Matos-Rocha TJ, Cavalcanti MGS, Barbosa-Filho JM, Lúcio ALSC, Veras DL, Feitosa APS. In vitro evaluation of schistosomicidal activity of essential oil of Mentha x villosa and some of its chemical constituents in adult worms of Schistosoma mansoni. Planta Med. 2013;79(14):1307-12.

18. Amaral RG, Fonseca CS, Silva TK, Andrade LN, França ME, Barbosa-Filho JM, et al. Evaluation of the cytotoxic and antitumour effects of the essential oil from Mentha $x$ villosa and its main compound, rotundifolone. J Pharm Pharmacol. 2015;67(8):1100-6.

19. Matos FJA, Machado MIL, Alencar JW, Matos MEO, Craveiro AA. Plants used in traditional medicine of China and Brazil. Mem. Inst. Oswaldo Cruz.. 1991;86(suppl 2):13-16.

20. Teles NSB, Fechine FV, Viana FAC, Viana IOL, Nascimento DF, Leite ALAS. Evaluation of the therapeutic efficacy of Mentha crispa in the treatment of giardiasis. Contemp Clin Trials. 2011;32(6):809-13.

21. Moraes ME, Cunha GH, Bezerra MM, Fechine FV, Pontes AV, Andrade WS. Efficacy of the Mentha crispa in the treatment of women with Trichomonas vaginalis infection. Arch Gynecol Obstet. 2012;286(1):125-30.

22. Guedes DN, Silva DF, Barbosa-Filho JM, Medeiros IA. Calcium antagonism and the vasorelaxation of the rat aorta induced by rotundifolone. Braz J Med Biol Res. 2004;37(12 ):1881-7.

23. Arruda TA, Antunes RMP, Catão RMR, Lima EO, Sousa DP, Nunes XP. Preliminary study of the antimicrobial activity of Mentha $x$ villosa Hudson essential oil, rotundifolone and its analogues. Rev Bras Farmacogn. 2006;16(3):307-11.

24. Lahlou S, Magalhães PJC, Carneiro-Leão RFL, Leal-Cardoso JH. Involvement of nitric oxide in the mediation of the hypotensive action of the essential oil of Mentha $x$ villosa in normotensive conscious rats. Planta Med. 2002;68(8):694-99.

25. Lima TC, da Silva TK, Silva FL, Barbosa-Filho JM, Marques MO, Santos RL, et al. Larvicidal activity of Mentha $x$ villosa Hudson essential oil, rotundifolone and derivatives. Chemosphere. 2014;104:37-43
26. Amaral RG, Fonseca CS, Silva TK, Andrade LN, França ME, Barbosa-Filho JM, et al. Evaluation of the cytotoxic and antitumour effects of the essential oil from Mentha $x$ villosa and its main compound, rotundifolone. J Pharm Pharmacol. 2015,67(8):1100-6.

27. Matos-Rocha TJ, Cavalcanti MG, Veras DL, Feitosa AP, Gonçalves GG, Portela-Junior NC L, et al. Ultrastructural changes in Schistosoma mansoni male worms after in vitro incubation with the essential oil of Mentha $x$ villosa huds. Rev Inst Med Trop Sao Paulo. 2016;58(1):7. doi.org/10.1590/S1678-9946201658004.

28. Neves BJ, Andrade CH, Cravo PVL. Natural products as leads in schistosome drug discovery. Molecules. 2015;20(2):1872-903.

29. Liang YS, Coles GC, Dai JR, Zhu YC, Doenhoff MJ. Adult worm tegumental damage and egg-granulomas in praziquantel-resistant and -susceptible Schistosoma mansoni treated in vivo. J Helminthol. 2002;76(4):327-33.

30. Mendonça AM, Feitosa AP, Veras DL, Matos-Rocha TJ, Cavalcanti MG, Barbosa CC, et al. The susceptibility of recent isolates of Schistosoma mansoni to praziquantel. Rev Inst Med Trop São Paulo. 2016;58:7. doi.org/10.1590/S1678-994620165800.

31. Moraes J De, Nascimento C, Lopes PO, Nakano E, Yamaguchi LF, Kato MJ. Schistosoma mansoni: in vitro schistosomicidal activity of piplartine. Exp Parasitol. 2011;127(2):357-64.

32. Bakkali F, Averbeck S, Averbeck D, Idaomar M. Biological effects of essential oils-a review. Food Chem Toxicol. 2008;46(2):446-75.

33. Eissa MM, El-Azzouni MZ, Amer EI, Baddour NM. Miltefosine, a promising novel agent for schistosomiasis mansoni. Int J Parasitol. 2011;41(2):235-42.

34. Esperandim VR, da Silva Ferreira D, Sousa Rezende KC, Magalhães LG, Medeiros Souza J, Pauletti PM, et al. In vitro antiparasitic activity and chemical composition of the essential oil obtained from the fruits of Piper cubeba. Planta Med. 2013;79(17):1653-5.

35. Godinho LS, Aleixo de Carvalho LS, Barbosa de Castro CC, Dias MM, Pinto PFS, Crotti AEM, et al. Anthelmintic activity of crude extract and essential oil of Tanacetum vulgare (Asteraceae) against adu adult worms of Schistosoma mansoni. Sci World J. 2014;2014:ID 460342. doi:10.1155/2014/460342. 